\title{
Early and late results of surgical treatment of congenital coronary artery fistula
}

\author{
A J J C BOGERS, J M QUAEGEBEUR, H A HUYSMANS
}

From the Department of Thoracic Surgery, University Hospital Leiden, Leiden, The Netherlands

ABSTRACT The early and late results of surgical treatment in 23 patients with congenital coronary artery fistula (CCAF) are presented. One patient died for reasons unrelated to the fistula during corrective surgery for an associated complex cyanotic abnormality. The patients with isolated CCAF and preoperative symptoms improved significantly after surgical closure of the CCAF $(p<0.05)$. We conclude that all symptomatic patients with CCAF should be treated with surgical closure of the fistula.

Congenital coronary artery fistula (CCAF) can be defined as a communication between a coronary artery and any cardiac chamber or great vessel without an interposed capillary bed. CCAF is a rare cardiac defect: less than 350 cases have been described. Nevertheless, several authors have reviewed the published reports. ${ }^{1-5}$ Liberthson et al were the first to show that patients with CCAF over 20 years of age had appreciably more symptoms and complications than those under $20 .^{3}$ Moreover, surgical treatment for CCAF in patients over 20 led to appreciably more postoperative complications than surgery in patients under $20 .^{3}$ We reviewed our own experience of surgical treatment for CCAF, comparing patients with and without symptoms regardless of their age.

\section{Patients and methods}

Between 1960 and 1985, 23 patients were operated on for closure of CCAF. Of these, 12 patients had CCAF as an isolated cardiac defect while 11 had other cardiac lesions as well (table 1). The diagnostic findings, and in particular the phonocardiographic findings, in eight of these patients have been published. ${ }^{6}$ We reviewed the history and the findings on auscultation, electrocardiography (ECG), chest radiography, cardiac catheterisation, coronary arteriography, and operation and compared the preoperative findings with those on postoperative

Address for reprint requests: Dr AJJC Bogers, Department of Thoracic Surgery, University Hospital Leiden, PO Box 9600, 2300 RC Leiden, The Netherlands.

Accepted 18 November 1986 follow up in the whole group and in patients with and without preoperative symptoms of CCAF as a solitary cardiac defect.

The findings of sex, age at presentation, and delay between angiographic or surgical diagnosis and operation are presented in table 2 . The age at operation ranged from five weeks to 73 years in the whole group, and from one to 51 years in those with isolated CCAF. In table 3 the patients with isolated CCAF are divided into those with and without symptoms. Before operation symptoms were present in seven patients: dyspnoea on exertion in three, past endocarditis in two, angina pectoris in one, and recurrent airway infections in one. Those with associated cardiac defects were not included in the analysis of functional class, auscultation, ECG, and chest radiographic findings in this study.

All patients with isolated CCAF showed a continuous murmur on auscultation. The ECG in all patients with isolated CCAF showed sinus rhythm; two patients with symptoms and two without showed abnormal repolarisation. Electrocardiographic evidence of left ventricular hypertrophy was present in three symptomatic patients and absent in the asymptomatic ones. Three of the symptomatic and none of the asymptomatic patients showed a cardiothoracic ratio above 0.5 on the chest radiograph.

Twenty one patients had cardiac catheterisation, with additional coronary arteriography in 18 , although this was usually not selective in the younger patients with associated cardiac anomalies. One patient with pulmonary stenosis and an atrial septal defect had no invasive investigation and was found to have a CCAF during the operation. The other patient without cardiac catheterisation was operated on 
Table 1 Congenital coronary artery fistula: anatomical origin and end of fistula and other cardiac defects

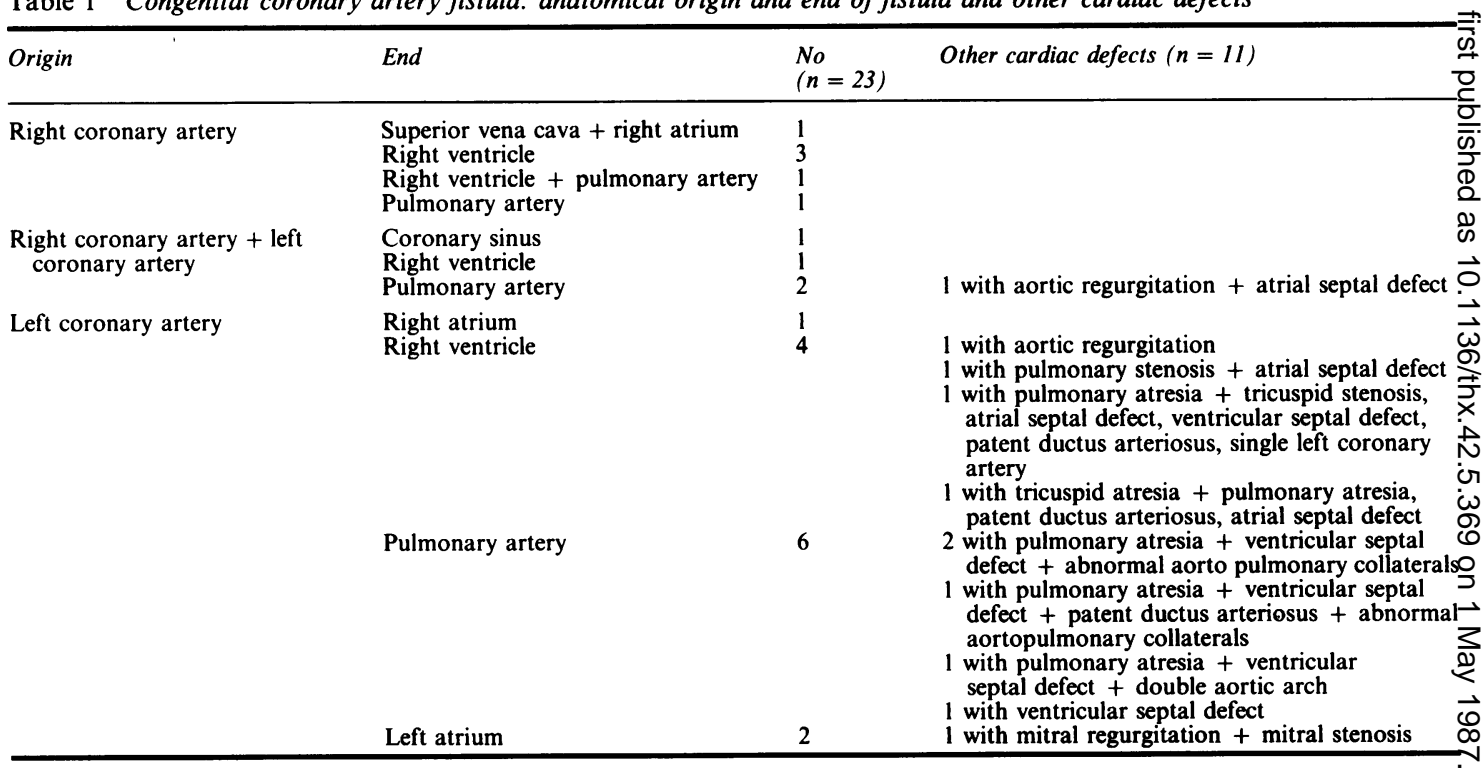

Table 2 Congenital coronary artery fistula: data from the whole group and from the patients with isolated congenital coronary artery fistula $(C C A F)$

\begin{tabular}{|c|c|c|}
\hline & Total group & Isolated CCAF \\
\hline $\begin{array}{l}\text { Sex }(M / F) \\
\text { Age at operation (y) (range) } \\
\text { Delay from diagnosis to operation (y) (range) } \\
\text { Postoperative follow up (y) (range) }\end{array}$ & $\begin{array}{l}7 / 16 \\
24 \cdot 3(0 \cdot 1-73) \text { (23 patients) } \\
2 \cdot 2(0-17)(23 \text { patients }) \\
6 \cdot 6(0 \cdot 3-22)(22 \text { patients })\end{array}$ & $\begin{array}{l}4 / 8 \\
18 \cdot 8(1-51)(12 \text { patients }) \\
1 \cdot 5(0-12)(12 \text { patients }) \\
7 \cdot 7(1-18)(12 \text { patients })\end{array}$ \\
\hline \multicolumn{3}{|l|}{ Functional class (NYHA) } \\
\hline $\begin{array}{l}\text { Derore operation } \\
\text { I }\end{array}$ & & 7 \\
\hline II & & 4 \\
\hline III & & 1 \\
\hline \multicolumn{3}{|l|}{ After operation } \\
\hline I & & 11 \\
\hline II & & 1 \\
\hline III & & 0 \\
\hline \multicolumn{3}{|l|}{ Oxymetric shunt } \\
\hline $\begin{array}{l}\text { Before operation } \\
\text { After operation }\end{array}$ & $1 \cdot 3(1 \cdot 0-2 \cdot 0)^{*} \dagger$ & $1 \cdot 3(1 \cdot 0-2 \cdot 0) \dagger$ \\
\hline \multicolumn{3}{|l|}{ Angiographic coronary stenosis } \\
\hline Before operation & & \\
\hline After operation & 2 (8 patients) & 2 (4 patients) \\
\hline
\end{tabular}

under the presumptive diagnosis of patent ductus arteriosus and in fact had a CCAF. Of the three patients who underwent cardiac catheterisation without coronary arteriography, one showed no shunting and had had a negative exploratory left thoracotomy for patent ductus arteriosus in another hospital. He was found to have a CCAF from the left coronary artery (LCA) to the left atrium. The second was a five week old boy who at operation was found to have a single LCA with a CCAF to the pulmonary artery in association with pulmonary atresia. In the third patient a CCAF was found during an operation for a ventricular septal defect. In addition, one of our patients had a persistent murmur after closure of a ventricular septal defect; during recatheterisation he showed persistent shunting, but no persisting ${ }^{\omega}$ ventricular septal defect. Coronary angiography showed a CCAF, which was closed in a second operation.

The anatomical location of the CCAF in our $23^{\stackrel{5}{+}}$ patients is given in table 1 . In four the fistula consisted $\frac{}{T}$ of a branching network with connections to vessels $\underset{\mathbb{C}}{\stackrel{O}{\circ}}$

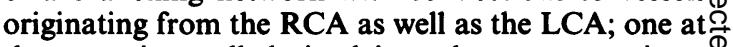
the posterior wall drained into the coronary sinus; $\stackrel{\mathbb{Q}}{\circ}$ one at the apex drained into the right ventricle through an intramural sinus, and two at the righto 
Table 3 Isolated congenital coronary artery fistula: patients with and without symptoms before operation

\begin{tabular}{llc}
\hline & With symptoms & Without symptoms \\
\hline Sex (M/F) & $1 / 6$ & $3 / 2$ \\
Age at operation (y) (range) & $24 \cdot 0(1-51)$ & $14 \cdot 2(4-38)$ \\
Delay from diagnosis to operation (y) (range) & $2 \cdot 0(0-12)$ & $0 \cdot 8(0-2)$ \\
Postoperative follow up (y) (range) & $6 \cdot 4(1-17)$ & $9 \cdot 4(4-18)$ \\
Functional class (NYHA) & & \\
Before operation & $2 *+$ & $5 *$ \\
I & 4 & 0 \\
II & 1 & 0 \\
III & $6 \dagger$ & 5 \\
After operation & 1 & 0 \\
I & 0 & 0 \\
II & 0 & $1 \cdot 1(1 \cdot 0-1 \cdot 2) \ddagger$ \\
Oxymetric shunt & $1 \cdot 5(1 \cdot 0-2 \cdot 0) \ddagger$ & 0 \\
Before operation & 0 & 0 \\
After operation & 0 & 0 \\
Angiographic coronary stenosis & & \\
Before operation & & \\
After operation & $2 \S$ & \\
\hline
\end{tabular}

${ }^{*} \mathrm{p}=0.05$ for the difference between seven patients with and five without symptoms.

$t \mathrm{p}<0.05$ for the difference before and after surgery in the seven patients with preoperative symptoms.

Excluding left-left fistulas.

$\S$ Coronary stenosis not in region of the previous fistula.

ventricular outflow tract drained into the pulmonary artery. Our series includes four cases of the rare combination of pulmonary atresia, ventricular septal defect, and CCAF from the LCA to the pulmonary artery. ${ }^{78}$

All patients with associated cardiac defects were operated upon with the use of a heart-lung machine. Of the patients with isolated CCAF, three were operated upon without a heart-lung machine. Eight fistulas were treated by interrupting the fistulous channels on the outside of the heart without opening the fistula, cardiac chamber, or great vessel. Six fistulas were treated by closing the anatomical distal end through the opened distal fistula. Eight fistulas were treated by closing their ends from the opened receiving cardiac chamber or great vessel. The twenty third patient died before an attempt was made at closing the fistula, during an operation for a complex congenital cardiac malformation (pulmonary atresia, tricuspid stenosis, atrial septal defect, ventricular septal defect, patent ductus arteriosus, and single LCA). This patient accounts for our hospital mortality.

Follow up of the patients was completed at their last outpatient visit (see tables 2 and 3 ). There were two late deaths. One patient with postoperative ventricular tachycardia died suddenly one year after correction of atrial septal defect, tricuspid atresia, pulmonary atresia, and patent ductus arteriosus. A second patient died 15 years after operation from a bronchial carcinoma. Before operation she had had dyspnoea on exertion. Her fistula was located between both coronary arteries and the coronary sinus, through which the CCAF was closed. Two years after operation coronary arteriography showed occlusion of a non-dominant right coronary artery and otherwise normal findings. Eight years after the fistula was closed she developed mitral valve prolapse and regurgitation associated with atrial fibrillation. Her activity state remained in functional class I (NYHA).

Coronary artery stenosis developed in a further patient in whom angina pectoris recurred eight years after operation. Before the operation this had been attributed to the CCAF, which was located between the circumflex artery and the pulmonary artery. The fistula was closed through the opened pulmonary artery. Eight years after operation the angina pectoris was attributed to $30 \%$ stenosis in the proximal circumflex artery and $60 \%$ stenosis in a small posterolateral branch, as shown by angiography, neither being in the region of the former fistula. In nine patients, including the two mentioned above, cardiac catheterisation was repeated. No more shunts, residual fistulas, or coronary artery stenoses were detected.

From the standpoint of statistical analysis the series is small. Therefore population samples are compared using Fisher's test of exact probability or the non-parametric Wilcoxon's rank sum test. Means are expressed with range, and $p$ values greater than 0.05 were considered not to be significant.

\section{Results}

In the group of patients with isolated CCAF we found no significant difference between those with and those without symptoms in preoperative auscultatory findings, pathological repolarisation, and left ventricular hypertrophy on ECG and cardiothoracic ratio on the chest radiograph. Patients with symptoms inevitably had a higher functional class 
(NYHA, see table 3).

At operation all 22 attempts at fistula closure were successful. One out of 23 patients died during an operation for complex cardiac malformation. During the postoperative stay in hospital two patients were treated for a postpericardiotomy syndrome, one patient had psychiatric problems, one patient had ventricular tachycardia necessitating medical treatment, and 18 patients had an uneventful recovery.

Postoperatively, all continuous murmurs in the patients with isolated CCAF, whether symptomatic or not, disappeared. In the symptomatic patients with isolated CCAF angina pectoris relapsed in one; all other symptoms disappeared after operation and no further instance of endocarditis occurred. Further clinical improvement in the patients with isolated CCAF was shown by the disappearance of left ventricular hypertrophy on ECG in two out of three patients, disappearance of pathological repolarisation on ECG in three out of four patients, and return of all cardiothoracic ratios to normal; however, these changes were not significant. The patients with symptomatic isolated CCAF showed a significant improvement in functional class $(p<0.05$; see table 3).

\section{Discussion}

Several reviews on CCAF have been published. ${ }^{1-59}$ Most agree that surgical treatment should be advised for patients with symptoms. For the asymptomatic CCAF patients Liberthson et al showed that those over 20 years of age had appreciably more problems related to their fistulas and more postoperative complications. Their conclusion was that all CCAFs should be closed early and electively. ${ }^{3}$

Our group of patients is comparable to those reviewed and reported elsewhere. ${ }^{1-610-12}$ In total we observed 558 preoperative patient-years, during which each of two patients-both with isolated CCAF - had an episode of endocarditis. Therefore in our series the risk of endocarditis in CCAF was 0.004 per patient-year. Only the reviews of Liberthson $\mathrm{et} \mathrm{al}^{3}$ and Rittenhouse $e t a l^{5}$ provide enough data to calculate the incidence of endocarditis in CCAF, which was 0.001 per patient-year in each report.

The delay between diagnosis and surgical treatment (tables 2 and 3 ) is of interest, because it represents the period of non-surgical or no treatment. In fact, for most of the patients this delay was the normal time between diagnosis and elective operation. Two patients with isolated CCAF were deliberately not operated on: one patient for three uneventful years until surgical closure was advised after the publication of Liberthson et al's paper ${ }^{3}$; the other patient for 12 years, at the end of which an episode of endocarditis took place, which was followed by surgical

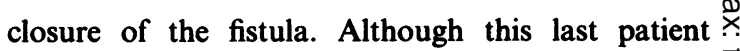
convinced us of the correctness of our surgical $\overrightarrow{\vec{s}}$ approach, some authors have doubts about surgical treatment $^{1314}$ and others report rare spontaneous regression or closure of CCAF. ${ }^{314}$ We did not $\frac{\bar{\sigma}}{\bar{n}}$ observe endocarditis during the follow up of our $\frac{\widehat{D}}{\mathrm{D}}$ patients.

The mechanism of angina pectoris produced by $\approx$ CCAF has been discussed by several $\overrightarrow{0}$ authors. $^{3511121516}$ Little has been said about the possibility of developing arteriosclerosis in the fistula $\vec{\omega}$ region in relation to surgical treatment. In our series, among the 18 patients who had preoperative coro- $x$ nary angiography none showed coronary sclerosis, $\stackrel{\vec{N}}{\mathrm{~N}}$ including the three patients with angina pectoris and $r$ an isolated CCAF. Postoperatively eight patients had ${ }_{0}$ a coronary angiography and two of these had coronary artery obstruction or narrowing, but not in the $\stackrel{?}{\rightarrow}$ region of the fistula; one of these had recurrent angina $\vec{z}$ pectoris attributed to newly developed stenosis elsewhere in his coronary arteries. Given these obser- vations we think that there is no correlation between $\biguplus_{\infty}$ closure of CCAF and the development of coronary. sclerosis in the region of the fistula.

The pitfalls in the diagnosis of CCAF have been pointed out. ${ }^{141117}$ As mentioned above, some of these occurred in the present series as well. ${ }^{6}$

The goal of surgical treatment of CCAF is closure $\stackrel{\varnothing}{\varnothing}$ of the fistula while preserving normal flow through $\overrightarrow{\vec{B}}$ the coronary artery. Different surgical techniques $\frac{3}{3}$ have been discussed, but all of them appear to be adequate, as there is only a very low rate of persistent or: recurrent CCAF. ${ }^{1569-11}$ In our series several methods of fistula closure were carried out with no recur-음 rence. Of our 23 patients, one with a complex congenital malformation died during surgery before an 0 attempt had been made at closing the fistula. This death is probably related more to the complexity of $ᄋ$ the congenital malformation than to the CCAF. The mortality in published reports of surgical closure of $ᄋ$ CCAF ranges from 0 to $6 \%$, and tends toward zero in $>$ recent reports. ${ }^{125912}$ The length of our follow up is given in tables 2 and 3. During follow up the patients with isolated CCAF who had symptoms beforesurgery significantly $(p<0.05)$ improved their func- $N$ tional class (table 3 ).

From our investigation we conclude that patientso with symptoms of CCAF should be treated by surro gical closure of the fistula. We think that elective sur- $\frac{\bar{\Phi}}{\mathbb{Q}}$ gical closure of CCAF in asymptomatic patients? should be seriously considered to prevent compli- $\square$ cations of the fistula and postoperative problems aftero surgery at a greater age. ${ }^{3}$

We thank Dr CH Arkema, Dr PB den Bakker, Dro LMH Bouwens, Professor B Buis, Dr MC Huige, $\operatorname{Dr}_{\varnothing}$ 
RJ Moene, Professor J Rohmer, and Professor JTC Vonk for allowing us to study data from patients under their care, and Mrs MB Boskemper for processing the manuscript.

\section{References}

1 Abott OA, Rivarola CH, Logne RB. Surgical correction of coronary arteriovenous fistula. J Thorac Cardiovasc Surg 1961;42:660-71.

2 Levin DC, Fellows KE, Abrams HL. Hemodynamically significant primary anomalies of the coronary arteries. Circulation 1978;58:25-34.

3 Liberthson RR, Sagar K, Berkoben JP, Weintraub RM, Levine FH. Congenital coronary arteriovenous fistula. Circulation 1979;59: 849-54.

4 Oldham HN, Ebert PA, Young WG, Sabiston DC. Surgical management of congenital coronary artery fistula. Ann Thorac Surg 1971;12:503-13.

5 Rittenhouse EA, Doty DB, Ehrenhaft JL. Congenital coronary artery-cardiac chamber fistula. Ann Thorac Surg 1975;20:468-85.

6 Roos JP, Hartman H, van der Schaar H, Brom AG. Diagnosis and surgical treatment of coronary artery fistula. Thorax 1970;25:259-66.

7 Kongrad E, Ritter DG, Hawe A. Pulmonary atresia or severe stenosis and coronary artery to pulmonary artery fistula. Circulation 1972;46:1005-12.

8 Rohmer J, Buis-Liem TN, Quaegebeur JM. Oorsprong. van de arteria pulmonalis uit de linker arteria coronaria bij pulmonalis atresie met ventrikel septum defect [abstract]. Ned Tijdschr Geneeskd 1986;130:710.

9 Meyer J, Reul GJ, Mullins CE, McCoy J, Hallman GL, Cooley DE. Congenital fistulae of the coronary arteries. J Cardiovasc Surg 1975;16:506-11.

10 Hallman GL, Cooley DE, Singer DB. Congenital anomalies of the coronary arteries: anatomy, pathology and surgical treatment. Surgery 1966;59:133-44.

11 Urrutia-S CO, Falaschi G, Ott DA, Cooley DE. Surgical management of 56 patients with congenital coronary artery fistulas. Ann Thorac Surg 1983;35:300-7.

12 Macri R, Capulzini A, Fazzini L, Cornali M, Verunelli F, Reginato E. Congenital coronary artery fistula. Thorac Cardiovasc Surg 1982;30:167-71.

13 Brooks CH, Bates PD. Coronary artery-left ventricular fistula with angina pectoris. Am Heart $J$ 1983; 106:404-6.

14 Jaffe RB, Glancy DL, Epstein SE, Brown BG, Morrow AG. Coronary arterial-right heart fistulae. Circulation 1973;48:133-43.

15 Ahmed SS, Harder B, Regan TJ. Silent left coronary artery-cameral fistula: probable cause of myocardial ischemia. Am Heart $J$ 1982;104:869-70.

16 Swank M, Koepke DE. Coronary artery to left atrium fistula requiring revascularisation: case report and literature review. Thorax 1982;37:376-80.

17 Dobell ARC, Long RW. Right coronary-left ventricular fistula mimicking aortic valve insufficiency in infancy. J Thorac Cardiovasc Surg 1981;82:785-9. 